\title{
Implementation of embedded real-time monitoring temperature and humidity system
}

\author{
Firdaus Hashim ${ }^{1}$, Roslina Mohamad ${ }^{2}$, Murizah Kassim ${ }^{3}$, Saiful Izwan Suliman ${ }^{4}$, \\ Nuzli Mohamad Anas ${ }^{5}$, Ahmad Zaki Abu Bakar ${ }^{6}$ \\ ${ }^{1,2,3,4}$ Faculty of Electrical Engineering, Universiti Teknologi MARA, 40450 Shah Alam, Selangor \\ ${ }^{5,6}$ Wireless Innovation, MIMOS Berhad, 57000 Bukit Jalil, Kuala Lumpur
}

\begin{tabular}{l}
\hline Article Info \\
\hline Article history: \\
Received Jan 17, 2019 \\
Revised Apr 26, 2019 \\
Accepted May 17, 2019 \\
\hline Keywords: \\
Arduino \\
Internet of things (IoT) \\
LoRaWAN \\
Monitoring system \\
The things network
\end{tabular}

\begin{abstract}
Temperature and humidity are among the parameters that significant to the industrial and agricultural. Traditionally, these elements are monitored inefficiently through wired monitoring system that caused higher implementation and maintenance cost. In addition, the device to detect the temperature such thermometer is not suitable for real-time monitoring since it need a longer response time to measure. With the advent of wireless technology, the temperature and humidity are monitored remotely and effectively. This paper aims to describe the implementation of an embedded real-time temperature and humidity monitoring system, using Arduino for Internet of Things (IoT) application. The system integrates the Arduino node with a dashboard system call Node-FRED, which interfaced to the LoRa radio through the Things Network gateway. This IoT application is deployed on both indoor and outdoor environment, to investigate the relation between the temperature and humidity level in order to manage the environment at more comfort level.
\end{abstract}

Copyright $(0) 2019$ Institute of Advanced Engineering and Science. All rights reserved.

\section{Corresponding Author:}

Roslina Mohamad

Faculty of Electrical Engineering

Universiti Teknologi MARA, Shah Alam, Selangor, Malaysia.

Email : roslina780@.uitm.edu.my

\section{INTRODUCTION}

Temperature and humidity are two elements that reflect the climate change of the worlds' today. The drastic changes of these parameters to the environment affect the life cycles of plants and animals. Temperature and humidity can assist the farmers to make a decision making for accurate agricultural production yield and monitoring the condition of fish farms [1-4]. Large scale buildings such skyscrapers, hotel and shopping malls have heating, ventilation and air-condition (HVAC). The changes of temperature and humidity on HVAC are two main factors that affect the environment conditions in the large scale building and increase the energy consumptions [5, 6]. The buildings that have the automatic HVAC systems can increase people's comfort and at the same it can reduce energy consumption.

Traditionally, a manual method by using mercury thermometer and analogue hygrometer are used to take the temperature and humidity. However, this method is not effective and put the burden to the daily chores. The reading process will take longer response time once the device performance deteriorating. Furthermore, the chemical substances in the measuring devices are exposed to the danger when its breakage due to poor handling [7]. Not to mentioned the limitation of this mercury thermometer that prone to human error when taking readings due to parallax errors or misleading data recording. In most cases, the analogue hygrometers could not react to the abrupt changes in humidity level as its need to be calibrated by hand as frequent as possible. 
The use of wired system to monitor the temperature and humidity may require higher cost implementation and maintenance [8], and increase adversely with the scale of deployment system. Thus, mobility features may ease the burden to monitor when a large area of implementation is to be considered. The wired system method had many disadvantage as compared with wireless method. Among the wireless system used to implement real time monitoring are Global System for Mobile (GSM), Wireless Fidelity (WIFI) [9],[10] and Low Power Wide Area Network (LoRaWAN) [11], [12]. Each of these technologies has its own advantages over the other that depends on the requirement and deployment scenarios. Therefore, the monitoring both of these parameters may be deployed remotely so as to maintain the environment condition always at the comfort of people's lives.

This paper describes the implementation of a real-time temperature and humidity monitoring system using Arduino platform. The Internet of Things (IoT) concept is leverage using LoRaWAN technology to monitor the parameters remotely. An indoor and outdoor deployment has been investigated, in which the temperature and humidity readings are presented using Node-RED platform. Section II of this manuscript provides the literature review, problem statement and the scope of this study. Section III describes the hardware design, software design and the technique towards achieving the research outcomes. Section IV discuss the result that had obtained from the research and finally conclude the works in the Section V.

\section{LITERATURE REVIEW}

At the age of technology centuries, with the advent of the wireless technology and the Internet of Things (IoT), human lifestyle become simpler in all aspects. The choices of automation systems show the rapidly increase in the number of users of internet over the past decade. The development of IoT devices to ensure the monitoring system method becomes more advanced in term of the user can accessed the data anytime and anywhere included within the remote area location [9],[10],[13]. Attempts had been made to implement systems that can benefits users by leveraging the IoT technologies.

Table 1 shows the previous works which had been conducted to implement real-time monitoring for diverse scenarios. Authors in [14] focused on the proper implementation of temperature and humidity monitoring to ensure that the tomato plants growth rapid and in good condition. The monitoring system able to determine the volume of water needed to get an ideal humidity for the plants environment. In other words, it helps to create a decision support to the users in determining the appropriate volume of water needed. The remote monitoring system helped the growth quality of the tomato plants, and can be further improved by adding more sensors. This would help farmers to widening the area of plantation easily.

Table 1. A review on the monitoring system method in previous study

\begin{tabular}{|c|c|c|}
\hline Authors & Research & Finding \\
\hline $\begin{array}{l}\text { M. U. H. Al Rasyid, E. M. } \\
\text { Kusumaningtyas, and F. } \\
\text { Setiawan, } 2016 \text { [14] }\end{array}$ & $\begin{array}{l}\text { Build a Monitoring system for temperature and humidity } \\
\text { as to determine the volume of water to get an ideal } \\
\text { humidity for tomato. The method that used it is by using } \\
\text { SHT75(temperature and humidity sensor) and using Xbee } \\
\text { as a gateway for transmit data to the server or application. }\end{array}$ & $\begin{array}{l}\text { Improvement the quality } \\
\text { of the tomato plant by } \\
\text { finding the suitable } \\
\text { amount of water to get the } \\
\text { ideal humidity for tomato }\end{array}$ \\
\hline $\begin{array}{l}\text { M. Bouyahi and T. } \\
\text { Ezzedine, } 2017 \text { [15] }\end{array}$ & $\begin{array}{l}\text { Create a Monitor the temperature and humidity in civil } \\
\text { structure by using the concept of Structural Health } \\
\text { Monitoring (SHM). This project method was used Zigbee } \\
\text { module wireless as communication data and Fibre Bragg } \\
\text { sensor as to detect the temperature and humidity. }\end{array}$ & $\begin{array}{l}\text { Understand the structure } \\
\text { to prevent the damage of } \\
\text { the structure occur and } \\
\text { prepare to repair it before } \\
\text { catastrophe failure }\end{array}$ \\
\hline $\begin{array}{l}\text { R. Do and E. Erdem, } 2015 \\
{[15]}\end{array}$ & $\begin{array}{l}\text { Monitor system for temperature and humidity to determine } \\
\text { the average of the temperature and humidity condition of } \\
\text { the tunnels in the dam. }\end{array}$ & $\begin{array}{l}\text { Understand the effect of } \\
\text { temperature and humidity } \\
\text { can prevent the damage of } \\
\text { tunnel in the dams by } \\
\text { controlling the air- } \\
\text { conditioning system. }\end{array}$ \\
\hline $\begin{array}{l}\text { H. N. Saha, S. Chaudhury, } \\
\text { R. Mukherjee, D. Paul, and } \\
\text { S. Haldar, } 2017 \text { [9] }\end{array}$ & $\begin{array}{l}\text { This previous study is research for monitoring health } \\
\text { patient over the internet (IoT application. The method that } \\
\text { had been used for this monitoring system is by detect the } \\
\text { temperature of the patient using LM } 35 \text { sensors and the } \\
\text { transmit data over the internet by using WI-FI ESP8266. }\end{array}$ & $\begin{array}{l}\text { Understanding the } \\
\text { concept of IoT and } \\
\text { Arduino application for } \\
\text { designing the monitoring } \\
\text { temperature system. }\end{array}$ \\
\hline
\end{tabular}

Temperature and humidity were also monitor in civil engineering using a concept called Structural Health Monitoring (SHM) [15]. This method was applied to ensure the real-time monitoring of any structure damaged as well as to evaluate the performance of the bridge structure under a heavy load. The method able to measure the temperature, humidity as well as strains in a concrete structure. Therefore, the bridge structure can be easily analyzed to detect damage as soonest before the catastrophic failure. A ZigBee network act as a backbone connecting the sensors within the monitored building. 
Another example of IoT technologies implementation in civil engineering field was the monitoring the condition of dams [15]. The system monitors the temperature and humidity inside the tunnels in the dam in order to control the average readings were always being in permissible condition to prevent further structural damages. Examples of real-time monitoring of temperature and humidity implemented in others fields such as manufacturing, medical, aquaculture and more, found in these literatures [6],[11], [17].

\section{METHODOLOGY}

The Thing Network (TTN) serves as the platform for the IoT devices to build and share abundant data connectivity. The LoraWAN technology allows the devices to talk each other as the alternative of more complex Wi-Fi or $3 \mathrm{G}$ connectivity $[18,19,20]$. An Arduino UNO microcontroller board is connected to Dragino LoRa shield, a long range transceiver based on the open-source library. Then, a customized circuit design consists of DHT22 sensor module is interfaced to the Arduino interface [21-23]. The calibrated temperature and humidity digital signal from DHT22 are transmitted to the TTN via LoRaWAN on AS923 frequency scheme. Figure 1 depicts the schematic diagram of Arduino (UNO) interface with Dragino Shield (Lora Radio) connected to DHT22 sensor while Figure 2 shows the system diagram respectively.

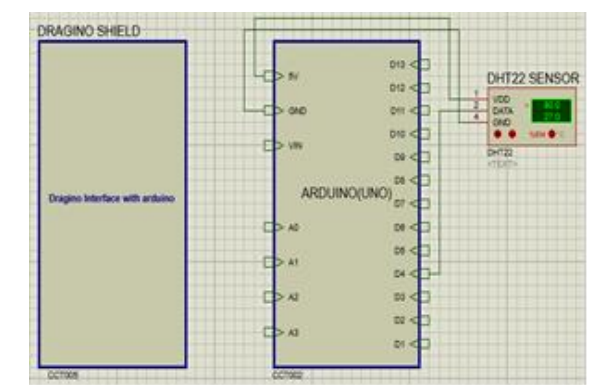

Figure 1. Schematic Diagram

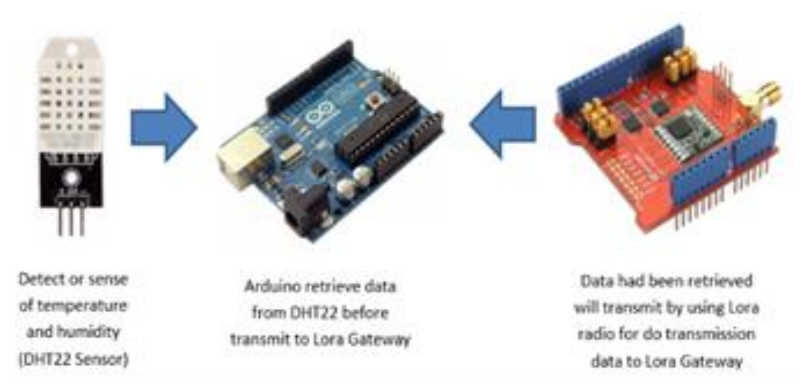

Figure 2. Hardware Requirements

Figure 3 shows the program code that had been written and executed to be shown the result on the Arduino IDE application through the serial monitor. The main part of the execution codes is divided into two part, to read the temperature and humidity respectively. The process is given specifically using the DHT.read22 API that retrieved the raw data from the DHT22 sensor. Apart from that, "int16 t" specifically differentiated the sensor being split into 2 bytes of data into the array (highByte and lowByte), as in LoRaWAN MAC protocol and transmitted to the LoRa Gateway [24], [25]. The raw data can be captured using the serial monitor application provided by the Arduino IDE. Furthermore, the real-time monitoring of the temperature and humidity from the Arduino UNO node can be manifested on the TTN application, as shown in Figure 4

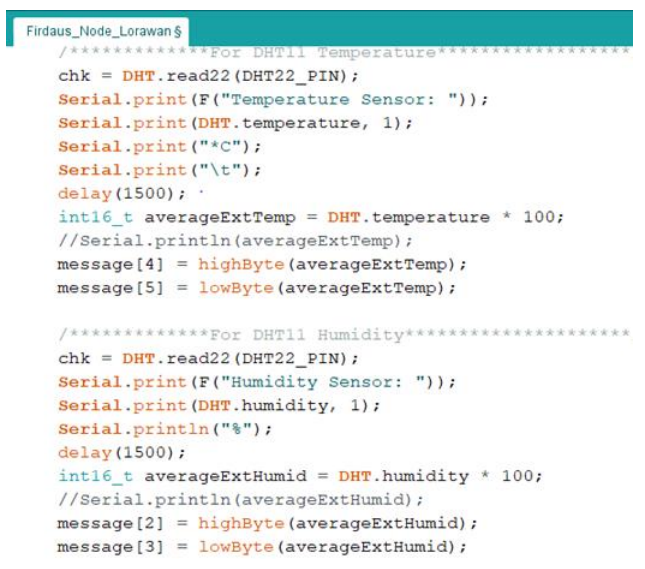

Figure 3. Programming Code

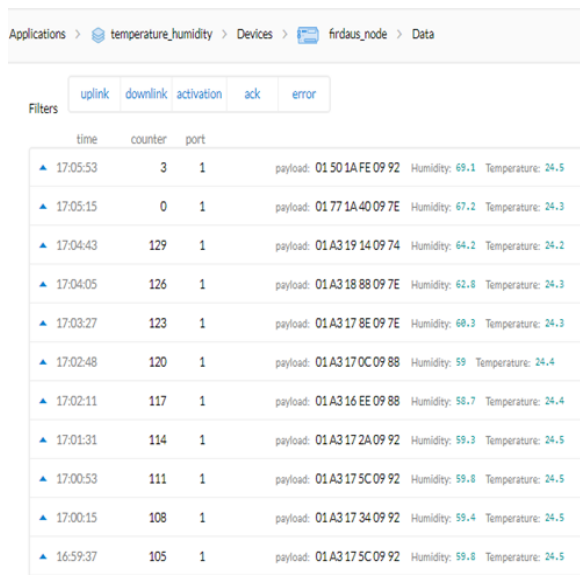

Figure 4. TTN Server Application 


\section{RESULTS AND DISCUSSIONS}

The experiment conducted in an outdoor and indoor environment, which located at PTAR lobby and two of the classrooms at the Engineering building of Universiti Teknologi MARA respectively. Those classrooms located at different floors, level 5 and 7, to replicate two different elevations as well as the environments were monitored days and nights. The experiments had been conducted to see the relationship between the monitored parameters to the environment condition being setup. This works also intends to present the deployment feasibility using LoRaWAN technology. The Things Network (TTN) server has been setup to collect the reading from sensors through the LoRa gateway. Then, the collected data are analyzed and presented using the Node FRED application.

The data collected in the evening at the classrooms are then displayed on the dashboard. Figures 5 and 6 depict the temperature and humidity reading respectively, (a) level 5 classroom and (b) level 7 classroom. For the comparison, the average temperature reading for level 5 classroom is much lower than the level 7 classroom by $5{ }^{\circ} \mathrm{C}$ difference. The average readings are $27{ }^{\circ} \mathrm{C}$ and $32{ }^{\circ} \mathrm{C}$ for level 5 and 7 classrooms, respectively. While for the humidity level, the level 5 classroom has the average reading of $58 \%$, much lower than the level 7 classroom of $69 \%$ reading.

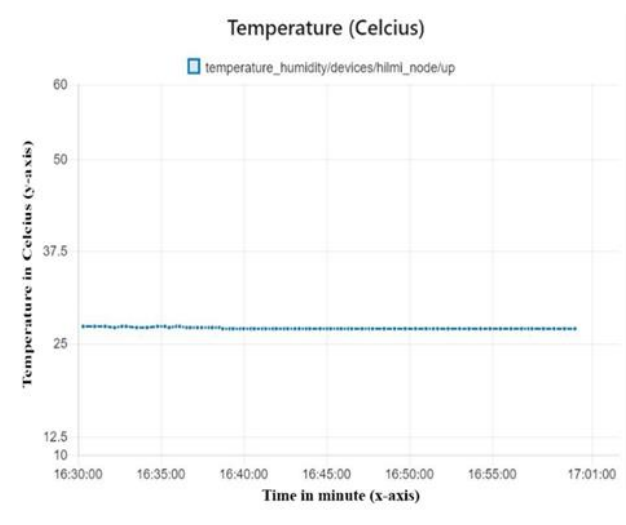

(a) Level 5

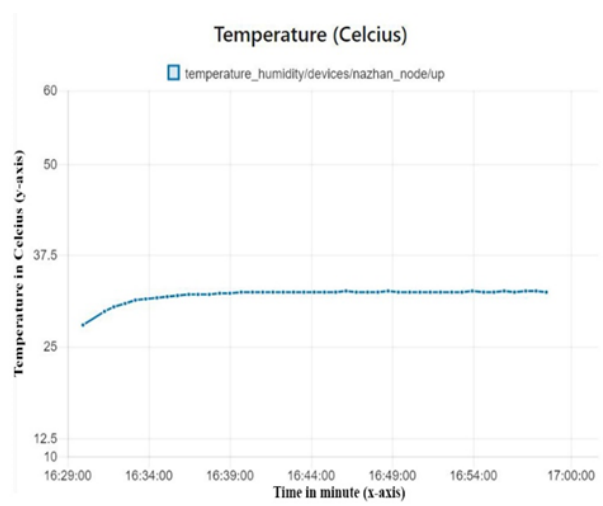

(b) Level 7

Figure 5. The reading of temperature $\left({ }^{\circ} \mathrm{C}\right)$ over time for indoor environment

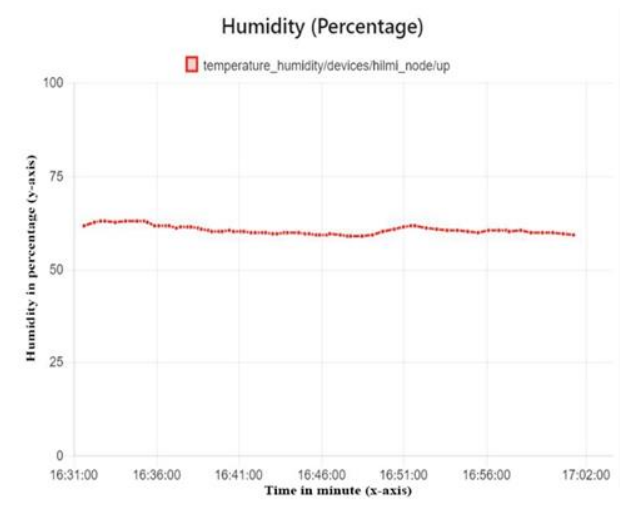

(a) Level 5

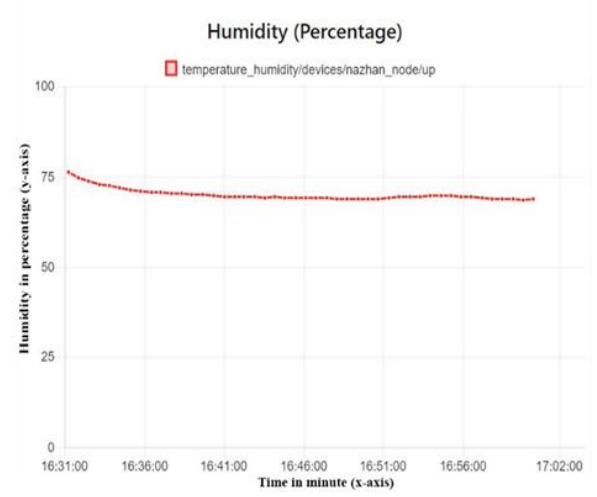

(b) Nights

Figure 6 . The reading of humidity (\%) over time for indoor environment.

Experiment also been conducted for the outdoor environment; hence, temperature and humidity readings have been measured at the lobby of Perpustakaan Tun Abdul Razak (PTAR). Furthermore, the observations been carried out day and night. From Figure 7, the temperature for the day (a) has higher than the night average readings with the difference of $7^{\circ} \mathrm{C}$. The average readings of two are $37^{\circ} \mathrm{C}$ and $30^{\circ} \mathrm{C}$, respectively. Meanwhile, the comparison of the humidity level for day and night (Figure 8), the average humidity during daytime was $65 \%$ while at night is $72 \%$. The difference by $7 \%$ in humidity indicated that the higher the percentage leads to rise air of moisture and showed that the temperature and humidity is inversely proportional. 


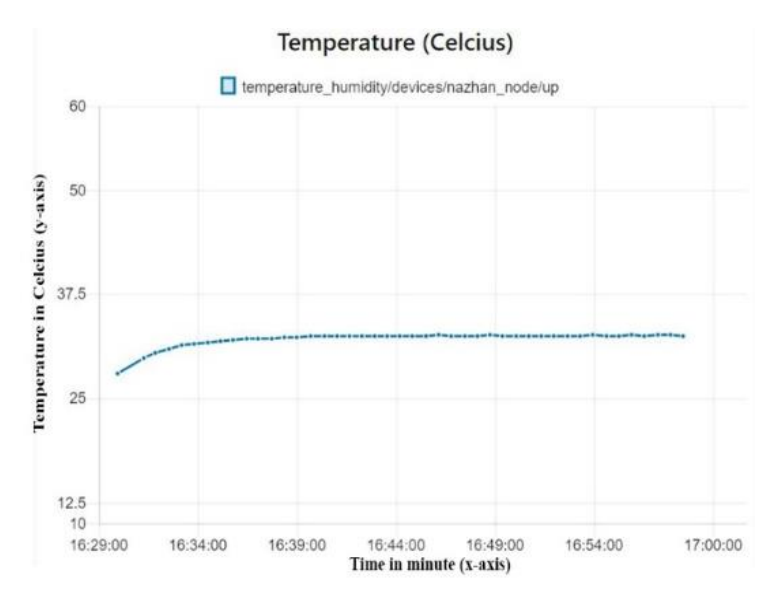

(a) Day

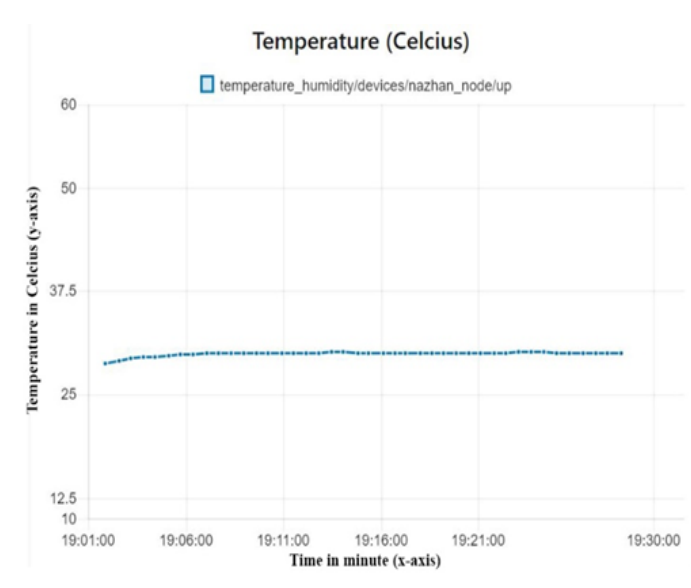

(b) Night

Figure 7 . The reading of temperature $\left({ }^{\circ} \mathrm{C}\right)$ over time for outdoor environment

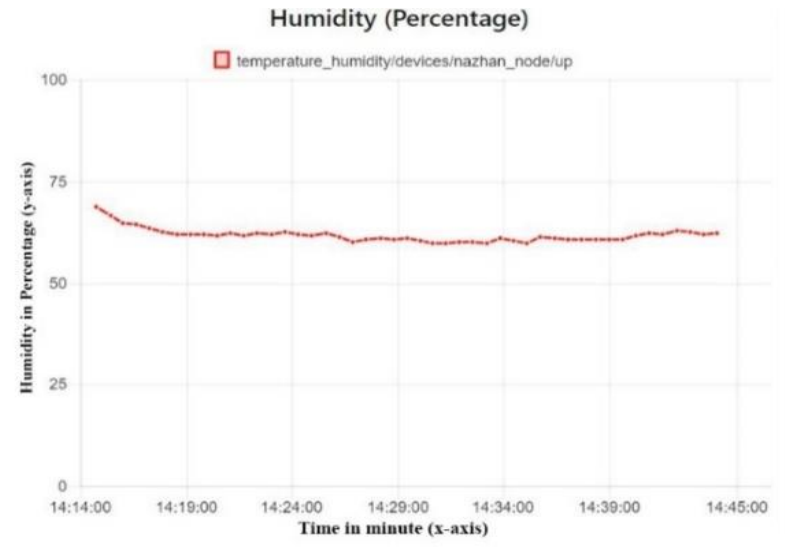

(a) Day

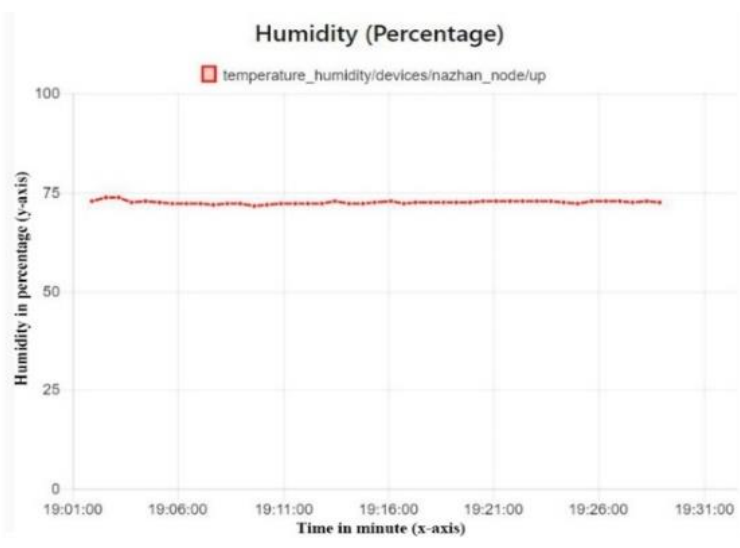

(b) Night

Figure 8 . The reading of humidity (\%) over time for outdoor environment

\section{CONCLUSION}

A real-time monitoring of temperature and humidity implemented using emebedded platform has been presented in this paper. The parameters were sensed wirelessly using Arduino UNO microcontroller. The platform was connected wirelessly to the sensors through the Dragino LoRa shield, in which a customized circuit consists of DHT22 sensor module interfaced to the Arduino module. The real-time monitoring system has been deployed in two scenarios, an indoor and outdoor environment. Furthermore, the studies observed the effect of the elevation to the temperature and humidity readings. The findings indicated that the temperature and humidity level in indoor environment correlated to the floor elevation. The monitored parameters increased with higher elevation floor. Meanwhile, the trend analysis for the temperature and humidity for outdoor envorinment was slightly different. When the temperature decreased at night, the humidity level increased and it can be infered that a lot of water vapour circulated in outdoor environment during night time.

\section{ACKNOWLEDGEMENTS}

The authors would like to thank Universiti Teknologi MARA (UiTM) and Minister of Higher Education (MOHE) for supporting this research through FRGS grants number FRGS/1/2017/ICT05/UITM/02/2 respectively. 


\section{REFERENCES}

[1] T. Cao-hoang and C. N. Duy, "Environment monitoring system for agricultural application based on wireless sensor network," 2017 Seventh Int. Conf. Inf. Sci. Technol., pp. 99-102, 2017.

[2] G. Deepika and P. Rajapirian, "Wireless sensor network in precision agriculture: A survey", in International Conference on Emerging Trends in Engineering, Technology and Science, ICETETS February 2016.

[3] Kshitij Shinghal et. al. "Wireless sensor networks in agriculture: For potato farming" International Journal of Engineering Science and Technology, Vol. 2(8), 2010, pp.: 3955-3963

[4] N. A. J. Salih, I. J. Hasan, et al., "Design and implementation of a smart monitoring system for water quality of fish farms", Indonesian Journal of Electrical Engineering and Computer Science (IJEECS), Vol. 14(1), pp. 44-50, 2019.

[5] C, S. A. "An Application of Building Automation System based on Wireless Sensor / Actuator Networks" Application of Information and Communication Technologies (AICT), 9th International Conference On

[6] N. A. Wahab, N. A. Sahril, et al., "Performance of Environmental and Energy Audit for Manufacturing Industrial Buildings" Indonesian Journal of Electrical Engineering and Computer Science (IJEECS) Vol. 12, pp. 534 541, 2018

[7] G. Wang, W. Wang, K. Li, and H. Liu, "A digital thermometer with fast response and high precision," 2014 7th Int. Conf. Biomed. Eng. Informatics, no. 61372047, pp. 504-510, 2014.

[8] D. Baghyalakshmi, T. Chandran, J. Ebenezer, and S. A. V. Satyamurty, "Wireless Sensor Network for temperature and humidity monitoring in a nuclear facility," 2013 5th Int. Conf. Adv. Comput. ICoAC 2013, pp. 205-211, 2014.

[9] S. Chaudhury, D. Paul, R. Mukherjee, and S. Haldar, "Internet of Thing based healthcare monitoring system," 2017 8th Ind. Autom. Electromechanical Eng. Conf. IEMECON 2017, pp. 346-349, 2017.

[10] G. Barbon, et. al. "Taking arduino to the internet of things: the asip programming model." Computer Communications, Vol. 89-90, pp: 128-140, 2016.

[11] A. H. Ali, R. F. Chisab, M. J. Mnati, "A smart monitoring and controlling for agricultural pumps using LoRa IOT technology" Indonesian Journal of Electrical Engineering and Computer Science Vol. 13, pp. 286 292, 2019.

[12] T. Ameloot, P. V. Torre, and H. Rogier, "A Compact Low-Power LoRa IoT Sensor Node with Extended Dynamic Range for Channel Measurements" Sensors (Basel). Vol. 18(7), pp. 2137, 2018.

[13] Harikrishnan, R. "An integrated xbee arduino and differential evolution approach for localization in wireless sensor networks". Procedia Computer Science, Vol. 48, pp. 447-453, 2015.

[14] M. U. H. Al Rasyid, et al., "Application to Determine Water Volume for Agriculture Based on Temperature \&amp; Humidity Using Wireless Sensor Network," 2016 Int. Conf. Knowl. Creat. Intell. Comput., pp. 105-112, 2016.

[15] M. Bouyahi and T. Ezzedine, "Design of smart Bridge based on WSN for efficient measuring of temperature, strain and humidity," 4th Int. Conf. Control Eng. Inf. Technol. CEIT 2016, pp. 16-18, 2017.

[16] R. Do and E. Erdem, "Temperature and Humidity Control of the Tunnels in the Dam Using Wireless Sensor Networks," 2015 IEEE 19th International Conference on Intelligent Engineering Systems (INES) pp. 379-383, 2015.

[17] T. Hardianto, B. Supeno, et al., "Design of Real Time Anemometer Based on Wind SpeedDirection and Temperature" International Journal of Power Electronics and Drive System (IJPEDS), Vol. 8, pp. 677 685, 2017.

[18] Adelantado, F., et al,’Understanding the Limits of LoRaWAN." IEEE Communications Magazine, Vol. 55(9): pp. 34-40, 2017.

[19] Reynders, B., et al.'Improving Reliability and Scalability of LoRaWANs Through Lightweight Scheduling." IEEE Internet of Things Journal, pp. 1830 - 1842, 2018.

[20] Abeele, F.V.d., et al., "Scalability Analysis of Large-Scale LoRaWAN Networks in ns-3." IEEE Internet of Things Journal, Vol. 4(6): p.p 2186-2198, 2017.

[21] E. S. Pramukantoro, et al, "Bridging IoT infrastructure and cloud application using cellular-based internet gateway device" Telecommunication, Computing, Electronics and Control (TELKOMNIKA), Vol. 17(3), pp. 1439-1446, 2019.

[22] M. Daud, V. Handika, and A. Bintoro, "Design And Realization Of Fuzzy Logic Control For Ebb And Flow Hydroponic System" Intl. Journal of Scientific \& Technology Research, Vol. 7(9), pp. 138-144, September 2018.

[23] D. Yolanda, et al, "Implementation of Real-Time Fuzzy Logic Control for NFT-Based Hydroponic System on Internet of Things Environment" IEEE 6th Int. Conf. on System Eng. and Tech. (ICSET), October 2016.

[24] N. A. Zainal, M. H. Habaebi, et al,, "Gateway sink placement for sensor node grid distribution in LoRa smart city networks" Indonesian Journal of Electrical Engineering and Computer Science (IJEECS), Vol. 14(2), pp. 834-842, May 2019.

[25] M. M. Agel, et. al, "Evaluation of MAC's Distributed Queuing Algorithm for Internet of Things Applications" Indonesian Journal of Electrical Engineering and Computer Science (IJEECS), Vol. 10(3), pp. 966 973, June 2018.

\section{BIOGRAPHIES OF AUTHORS}

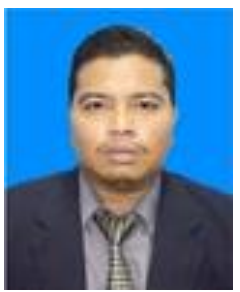

Firdaus Hashim obtained certified of Diploma in Electrical Engineering in Instrumentation field at Universiti Teknologi Mara Campus Dungun, Terengganu in year of 2015. Then, he continues studies and official obtained the certified of B. Eng. Degree in Electronic Engineering in Computerization field at Universiti Teknologi Mara Shah Alam, Selangor in 2018. His research interests are in wireless sensor networks, embedded systems, network security, Internet of Things (IoT) and cloud computing. 

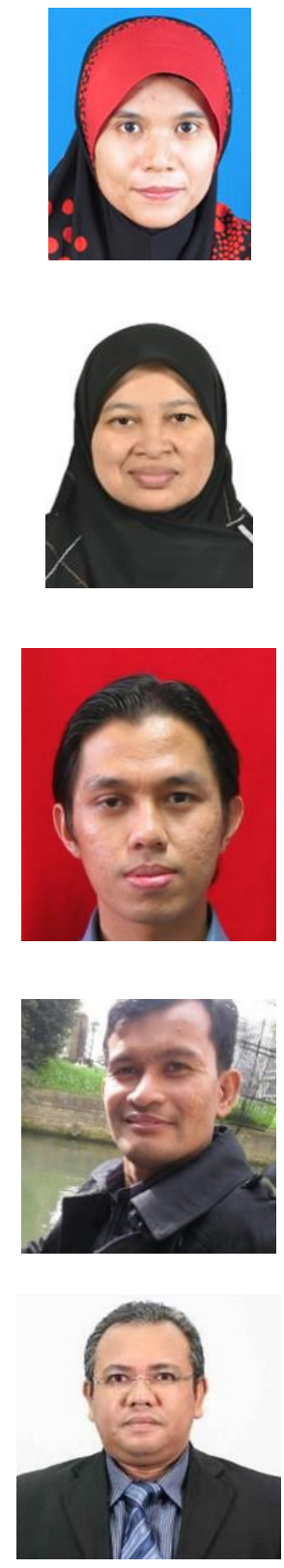

Roslina Mohamad obtained the B. Eng. degree in Electrical Engineering and M. Eng. Science degree from Universiti Malaya, Kuala Lumpur in 2003 and 2008 respectively. She received the $\mathrm{PhD}$. degree in Aerospace Engineering from Universiti Putra Malaysia, in 2016. From 2006 until now, she is with Faculty of Electrical Engineering, Universiti Teknologi MARA, as a senior lecturer. She has been appointed as a Head of Computer Engineering Studies at the same institution since 2018. Her research interests are in computing algorithm and digital signal processing for deep space communication, channel coding, theory of computation, and wireless communication.

Murizah Kassim is currently working as senior lecturer at Faculty of Electrical Engineering, Universiti Teknologi MARA, Shah Alam, Selangor. She received her PhD in Electronic, Electrical and System Engineering in 2016 from the Faculty of Built Environment and Engineering, Universiti Kebangsaan Malaysia (UKM), Malaysia. She has published many papers related to computer network, Internet of Things (IoT), Web and mobile development applications research. She has experienced about 19 years in technical team at the Centre for Integrated Information System, UiTM Shah Alam. She is also the member of Enabling Internet of Things Technologies (ElIoTT) research group UiTM. She joined the academic since January 2009 and currently member of IEEE, IET, IAENG and IACSIT organization.

Saiful Izwan Suliman is a senior lecturer at the Faculty of Electrical Engineering, Universiti Teknologi MARA (UiTM), Malaysia. He obtained 1st class degree in Artificial Intelligence in 2002 and Master of Science (Electrical Engineering) from UiTM in 2006. His Phd was awarded by The University of Nottingham, UK in 2015. His research interest is mainly in the area or artificial intelligence, optimization and pattern recognition algorithm, metaheuristic approach, frequency bandwidth spectrum and power system operations. He has published papers in many international conferences as well as reputable journals. He is a certified Professional Technologist and Chartered Engineer (CEng) with IET, UK. He is currently the head of ICT Unit, Institute of Research Management and Innovation at UiTM.

Nuzli Mohamad Anas (SM'14) received his B.Eng. and M.Eng. in electrical engineering from the Universiti Teknologi Malaysia, in 2000 and 2013, respectively. From 2008, He works as Senior Researcher at Wireless Communication Lab in MIMOS Berhad. He is currently pursuing his PhD in Computer and Communication System Engineering at Universiti Putra Malaysia. His research interest in the areas of wireless mobile communications and signal processing, especially on cognitive radio and physical-MAC layer communication design.

Ahmad Zaki is currently the Senior Staff Engineer of the Wireless Innovation laboratory in MIMOS. His primary role is to realize inter-communication between various hardware devices in terms of embedded software programming. He is also responsible to design and implement device's end-to-end software flow for the integration with MIMOS IOT platform. He has vast working experience with various roles and responsibilities within the embedded system development in multinational and local companies. He holds a Bachelor Degree in Electrical and Electronics Engineering from Salford University, United Kingdom. Ahmad Zaki holds 11 patents (2 granted, 9 filed). 